\title{
EMBRYOGENY OF ARISAEMA TRIPHYLLUM
}

J A M E ELLIS Gow

\section{(WITH TWENTY-FOUR FIGURES)}

This species is interesting as a representative of the lower monocotyledons, and as an extreme type of its family. If, as suggested by ENGLER, those aroids which possess hermaphrodite flowers are to be taken as the primitive type of the family, and the monoecious genera are to be considered as reduced forms, Arisaema must be regarded as an example of extreme reduction, since it is usually dioecious. According to this view, it should stand farthest in point of development from the original prototype of the aroid family, and although it does not show as complex a structure as do other genera, it should be considered as having probably undergone a longer course of development than they. But it seems quite as reasonable to suppose that the monoecious genera are the more primitive forms, and if this view be accepted, Arisaema must take its place at the foot of the list, as the least differentiated form. If the former hypothesis be accepted, we must regard the occasional monoecism of this species as a case of reversion; if the latter, it must be regarded as a variation which is strictly in accord with the general tendency of the family. It is plain, however, that the problem cannot be solved by merely using the monoecism or dioecism of the species as a basis for classification, but that its whole life-history must be taken into account; and even then the question cannot be answered satisfactorily until the life-histories of all the aroid genera have been worked out with far greater completeness than has yet been done.

The material here described was all gathered in the vicinity of Iowa City, Iowa, during the summer of r9or. A part of it was worked up during the following winter, but it was found necessary to drop the work, and the later phases were not undertaken until the present year. All ovaries were cut out one by one, or in groups of four or five, killed and fixed in I per cent. acetic acid, sectioned in paraffin to a thickness of 2-5 $\mu$, and stained with Delafield's hematoxylin, Haidenhain's Botanical Gazette, vol. 45] 
iron-alum-hematoxylin, or safranin and gentian-violet. In the latter case a saturated solution of each stain in anilin water was used, and very excellent results were obtained.

\section{MEGASPORANGIUM}

The ovary of Arisaema contains one to six erect, orthotropous. ovules $(f i g . I)$. The ovules in over three hundred ovaries were counted, and the average number was found to be four (fig. 2). They

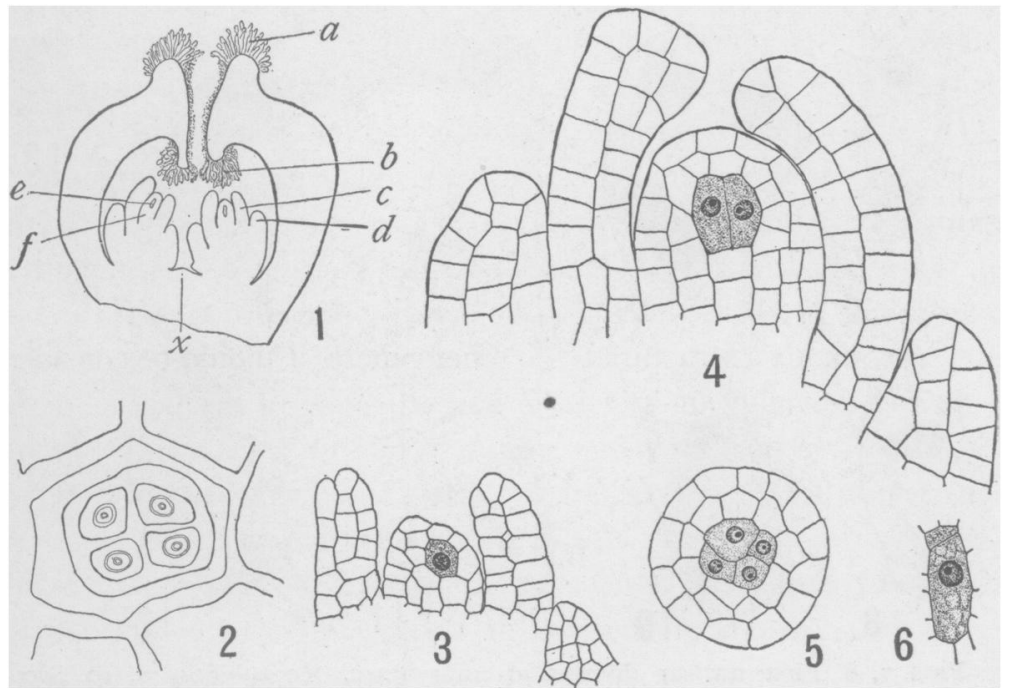

FIG. I. Ovary of Arisaema: $a$, stigma; $b$, conducting cells; $c$, inner integument; $d$, outer integument; $e$, embryo sac; $f$, nucellus; $x$, end of axis. $\times 36 .-F i g .2$. Transverse section of ovary. $\times 36$.-FIG. 3 . Archesporial cell; contents of surrounding cells not drawn. $\times 385$.-Fig. 4. Two sporogenous cells resulting from vertical division of archesporium. $\times 400 .-F I G .5$. Cross-section of nucellus showing four sporogenous cells. $\times 400 .-F I g .6$. Division of sporogenous cell. $\times_{400}$.

are probably lateral in origin, although at first glance they appear to be axial. The occurrence of four ovules grouped equilaterally about a slight protuberance in the middle of the base of the ovary (fig. $I, x$ ) would indicate the latter as the suppressed apex of the axis. This reminds one somewhat of the suppression of the axis in Dieffenbachia, ${ }^{\mathbf{1}}$ except that in Arisaema the suppression is much more complete.

I Campbell, D. H., Studies on the Araceae. Annals of Botany 14: I-25. pl. $I$. I900. 
The earliest material was collected during the first week in April. At that time the ovules appear as minute protuberances from the base of the ovary, the inner integuments have just begun to show, and the cells of the nucellus are as yet undifferentiated. The ovule grows with great rapidity, the outer integument soon appears, and the inner integument passes beyond the apex of the nucellus. At the same time the nucellus itself increases greatly in size, and the
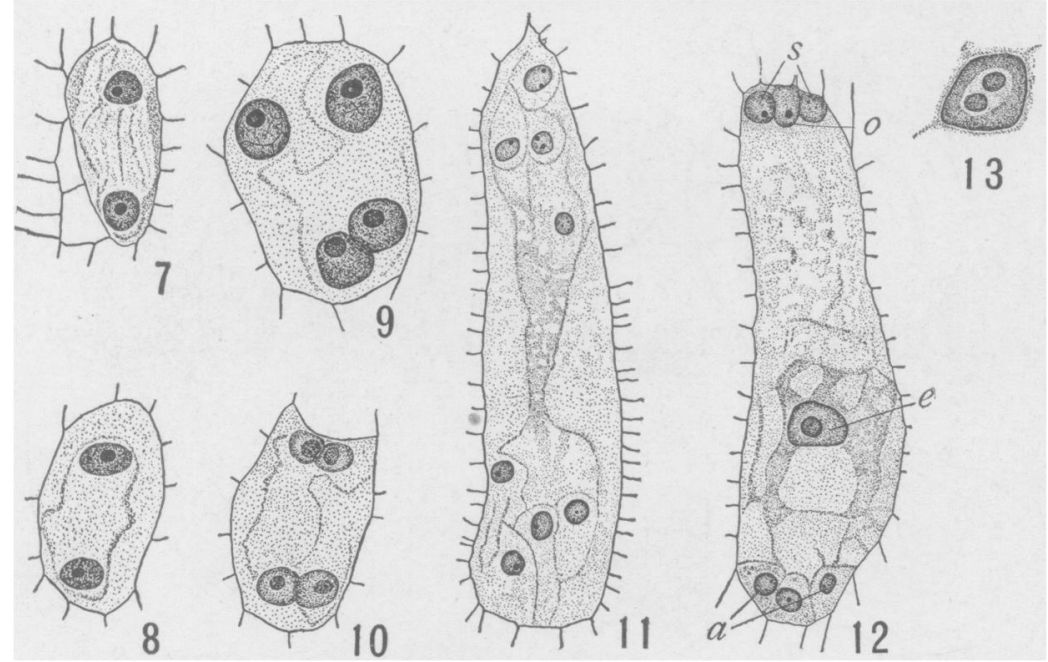

FIGs. 7, 8. First nuclear division of embryo sac. $\times 920 .-F i g s .9$, Io. Second division in embryo sac. $\times 920 .-F I G$. II. The eight-nucleate embryo sac. $\times 920 .-$ FIG. I2. Embryo sac after fusion of polar nuclei; index letters suggest the structures. $\times 920 .-F I G . ~ I 3$. Binucleolate endosperm nucleus. $\times 920$.

archesporial cell, recognizable by its greater size and more definite reaction to stains, makes its appearance in the hypodermal layer (fig. 3). This is followed by a periclinal division of the epidermal cells of the nucellus. The first two divisions of the archesporial cell are by anticlinal walls at right angles to each other, thus giving rise to four sporogenous cells lying side by side (figs. 4, 5). One of these outstrips the others in its growth, crowding them and the surrounding cells of the nucellus. It undergoes one transverse division, by which a small cell, frequently with an ill-defined nucleus, is cut off (fig. 6). Whether this is a tapetal cell, or one of a "row of two" formed by a mother cell, was not determined. At this stage the 
inner (functioning) cell is usually $\circ . \mathrm{I}^{\mathrm{mm}}$ in length, and its nucleus, by successive divisions, gives rise to the usual eight nuclei of the embryo sac (figs. 7-II). The oosphere, synergids, and antipodal cells are organized as usual, and the polar nuclei fuse (fig. I2). The fusion endosperm nucleus frequently contains two nucleoli (fig. I3).

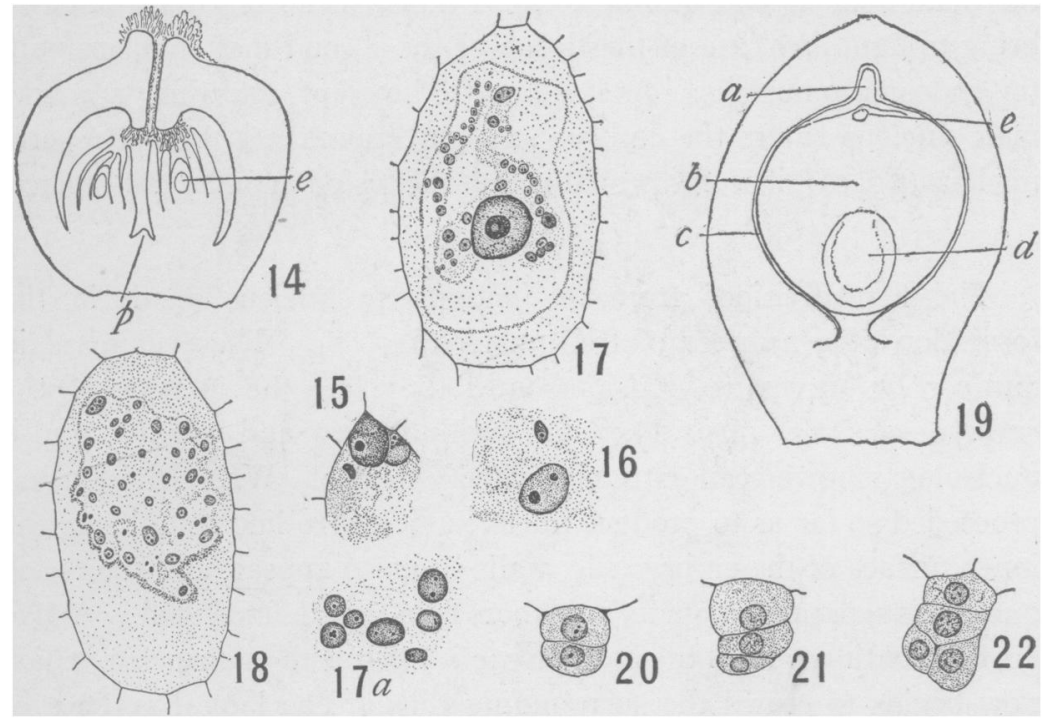

Fig. I4. Ovary at period of fertilization; $e$, embryo sac; $p$, placenta. $\times 36$. Fig. I5. Oosphere and male nucleus. $\times 920 .-$ Fig. I6. Endosperm nucleus and

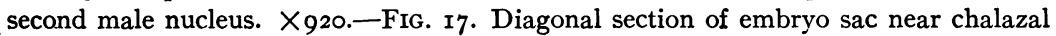
extremity, showing endosperm and, probably, one antipodal dislodged by knife. $\times 920$. -FIg. I7a. Endosperm nuclei enlarged. $\times 2050 .-F I g . ~ 18$. Endosperm nuclei. $\times 920$. -FIg. I9. Longitudinal section of endosperm $(b)$, surrounded by remains of inner integument $(c)$, and of nucellus $(a)$, and containing embryo $(e)$, and large vacuole $(d)$. XI4.-Fig. 20. Two-celled embryo. $\times 920 .-F i g . ~ 21$. Three-celled embryo. $\times 920 .-$ Fig. 22. Four-celled embryo. $\times 920$.

When the nuclear divisions are complete, the embryo sac has increased to a length of about $0.35^{\mathrm{mm}}$. The lateral cells of the nucellus have been greatly crowded, but its tip remains intact. The inner and outer integuments have grown until they press against the conducting cells in the roof of the ovary (fig. I4).

\section{FERTILIZATION}

The stigma of Arisaema consists of a mass of loosely compacted, somewhat mucilaginous papillae (fig. II). The pollen tube finds 
access to the interior of the ovary through an open style which is more or less filled with a loose mass of conducting cells, the lower ones extending well down into the cavity of the ovary (fig. I4.) The pollen tube enters by the micropyle, and a number of sections were obtained showing it penetrating the nucellus. One section showed the male nucleus and oosphere ( $f$ ig. I5), but careful search failed to bring to light any case of the fusion of the second male nucleus with the endosperm nucleus. As it is known, however, that this "second" male nucleus enters the embryo sac and approaches the endosperm nucleus ( $f g . I^{\prime}$ ), it seems probable that the fusion actually takes place.

\section{ENDOSPERM}

The first divisions from the endosperm nucleus result in the formation of a number of free nuclei ( $f g .{ }^{17}$ ). These increase in number by successive divisions until they line the interior of the embryo sac ( $f g$. I 8 ). They are well defined and usually multinucleolate, showing an extreme diversity in size. When division has proceeded so far as to produce nuclei sufficient to line completely the inner surface of the embryo sac, walls begin to appear, and soon each nucleus is separated from its neighbors by a well-defined wall. Active growth continues until the embryo sac is filled with endosperm, which now begins to crowd the surrounding cells. The lateral vestiges of the nucellus disappear, as a result of this pressure, and the inner integument is stretched until it becomes finally nothing more than a thin limiting membrane surrounding the endosperm. The outer integument remains intact, its growth keeping pace with the growth of the endosperm. The persistent tip of the nucellus likewise remains intact, and even increases in size. The cells in the base of the nucellus are greatly crowded, and many of them break down. When the endosperm has reached its full size, it is about $3^{\mathrm{mm}}$ in length, and consists of two well-defined parts (fig. I9). The upper part (b) consists of cells with thin but well-defined walls and at first a distinct nucleus; later they are filled with starch grains. In the lower part of the endosperm there is developed a large vacuole $(d)$.

\section{EMBRYO}

In the specimens examined, the first division of the oospore does not occur until the formation of endosperm is well under way. As 
it appears that endosperm formation does not begin until after the pollen tube has reached the embryo sac (and probably not until the endosperm nucleus and the second male nucleus have fused), it would seem that the fertilization of the oosphere is followed by a period of rest before the formation of the embryo begins. The first two divisions are transverse, followed by a longitudinal division ( $f g s$. 20-22). Beyond this point no definite history of the embryo can be

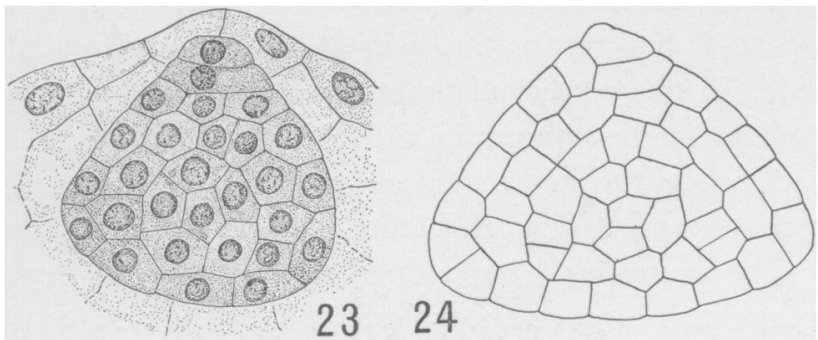

FIG. 23. Longitudinal section of embryo imbedded in endosperm. $\times 770 .-$ Fig. 24. Same, at somewhat later stage of development. $\times 770$.

given until the stage illustrated in fig. 23 is reached. The embryo here shown is six weeks or two months old and has not yet reached its maximum development; fig. 24 shows a somewhat older embryo. Beyond this stage no good sections of the embryo were obtained.

\section{SUMMARY}

Although the dioecious character of Arisaema would indicate for it a very low place among the aroid genera, other characteristics do not entirely bear out this view. The erect and orthotropous ovule, it is true, seems to indicate it as a primitive form, but the fact that there are four ovules (typically) in each ovary, and that their basal origin is apparent only, since they are in reality lateral outgrowths of the suppressed axis, seems to prove it a more highly specialized type than Aglaonema, Nephthytis, and Spathicarpa, in all of which each carpel contains a single basal ovule. This view is confirmed if we consider the variations in the number and arrangement of the nuclei in Nephthytis and Aglaonema (CAmpBell, l.c.) as indicating their primitive character. The development of the embryo sac in Arisaema corresponds to the usual type found in other angiosperms, and gives no hint of its possible affinities with lower forms. On the 
other hand, the early presence of a number of sporogenous cells in the nucellus appears to ally it with the two genera mentioned, both of which exhibit a similar peculiarity.

The development of endosperm in the aroids is usually characterized from the beginning by the formation of prominent cell walls. This characteristic has been noted by CAmpBell (l.c.) in Anthurium, Nephthytis liberica, and Lysichiton, and by myself in Nephthytis Gravenreuthii. Arisaema is an exception in that the first formation of endosperm is by free nuclear division, although cell walls are soon developed. In this respect it resembles Dieffenbachia daraquiniana, whose embryo sac becomes quite filled with endosperm nuclei before the cell walls begin to make their appearance. The resemblance of the suppressed axis to that of Dieffenbachia has already been mentioned. The anatropous character of the ovule in the latter genus, the fact that each of the two ovules is inclosed in a separate carpel, and the fact that there is only one archesporial cell, and that the primary parietal cell originates at its inner instead of its outer end, serve to draw a broad distinction between it and Arisaema, in spite of the resemblance in endosperm formation. The peculiarities mentioned would probably indicate that Dieffenbachia is a somewhat less primitive form than Arisaema, and one whose development has proceeded along different lines. The presence of staminodia among the pistillate flowers also appears to bear out this view.

Arisaema, therefore, appears to be a more highly developed form than Spathicarpa, Aglaonema, and Nephthytis, but somewhat more primitive than Dieffenbachia, and much more primitive than Anthurium, Spathyema, Orontium, and Acorus, since all the latter have perfect flowers.

When the foregoing was written, the writer was not aware of the existence of a paper by MotTIER ${ }^{2}$ on the development of the embryo sac in Arisaema. A comparison of the two papers, however, shows that they do not cover the same ground, since Motrier limited his investigation to the earlier phases, and did not discuss the development of the endosperm, the growth of the embryo, or the possible affinities of the species.

GREENFIELD, Iowa

2 Mottier, D. M., On the development of the embryo sac of Arisaema triphyllum. Bot. Gazette 17:258-260. pl. I8. I892. 